\title{
Removal of Zinc onto Several Adsorbents Derived from Waste Activated Sludge of Crumb Rubber Industry (CRI-WAS)
}

\author{
Salmariza.Sy ${ }^{\#}$, Harmiwati ${ }^{*}$, Desy Kurniawati ${ }^{\wedge}$, Hermansyah Aziz ${ }^{+}$, \\ Zulkharnain Chaidir ${ }^{3}$ and Rahmiana Zein ${ }^{3}$ \\ ${ }^{\#}$ Institute for Research and Standardization of Industry Padang, Indonesia \\ E-mail: rizasalma@yahoo.com \\ *Department of Chemical Engineering of Natural Product, Polytechnic ATI Padang, Indonesia \\ E-mail: harminahar@gmail.com \\ ^Department of Chemistry, Padang State University, Padang, Indonesia \\ E-mail:desy.chem@gmail.com \\ ${ }^{+}$Laboratory of Analytical Environmental Chemistry, Department of Chemistry, \\ Faculty of Mathematics and Natural Sciences, Andalas University, Indonesia \\ E-mail: haziz13@yahoo.com,zulkarnain_ch@yahoo.com,mimiedison@yahoo.co.id
}

\begin{abstract}
Waste activated sludge of crumb rubber industry (CRI-WAS) is discarded as waste from wastewater treatment processing. Therefore it is necessary to develop and innovate to convert the material becomes valuables and expected to be an economical adsorbent for metal ion remediation from wastewater. The ability of three types of adsorbents prepared from CRI-WAS for the removal of $\mathrm{Zn}$ (II) from aqueous solutions has been investigated. The XRF, BET, SEM-EDX, and FTIR analysis were conducted to characterize the PS (pure sludge), WS (washed sludge) and P600 (pyrolysis at $600^{\circ} \mathrm{C}$ ) CRI-WAS types of adsorbents. In the batch system, experimental parameters were investigated, including solution $\mathrm{pH}$, contact time, and adsorbent dose. The data were analyzed by analysis of variance (ANOVA) and a further test Duncan's New Multiple Range Test (DNMRT) at the 5\% significance level. The results reveal that all types of adsorbent exhibited good sorption potential at pH 5.0. The P600 has largest adsorption capacity. The maximum adsorption capacity of the adsorbent for $\mathrm{Zn}$ (II) was found to be $10.276 \mathrm{mg} \mathrm{g}^{-1}, 11.042 \mathrm{mg} \mathrm{g}^{-1}$ and $64.169 \mathrm{mg} \mathrm{g}^{-1}$ for PS, WS and P600 CRI-WAS types of adsorbents respectively. The results showed that the adsorption isotherm data were fitted well by the Langmuir isotherm.
\end{abstract}

Keywords - crumb rubber industry; waste activated sludge; PS; WS; P600 CRI-WAS adsorbents; Zn(II)

\section{INTRODUCTION}

Contamination of water by toxic heavy metals through the discharge of industrial wastewater is a worldwide environmental problem. Rapid industrialization has seriously contributed to the release of toxic heavy metals to water streams. Zinc is considered as an essential element for life and acts as a micronutrient when present in trace amounts. It is important for the physiological functions of living tissue and regulates many biochemical processes. Elevated levels of zinc result in health problems. Symptoms of zinc toxicity include irritability, stomach cramps, muscular stiffness, loss of appetite, vomiting, and nausea [1], [2]. The metal is further reported to be bioaccumulated into flora and fauna creating ecological problems. World Health Organization [3] recommended a level of zinc in drinking water is $5 \mathrm{mg} / \mathrm{L}$. The quality of wastewater discharge limit of zinc for effluent in Indonesia is $5 \mathrm{mg} / \mathrm{L}$ [4]. Most zinc enters the environment as the result of human activities such as flooding of ore mines, alkaline zinc-manganese batteries, purifying zinc, steel production, and coal burning and burning of wastes. Zinc is also present in high concentration in wastewater of pharmaceuticals, galvanizing, paints, pigments, insecticides, cosmetics, etc. that causes serious problem to the environment [5], [6].

Various technologies have been examined for eliminating the weight of the metal ions from aqueous media. For example chemical precipitation, electrodialysis, ion exchange, reverse osmosis, Membrane filtration, coagulation, solvent extraction and adsorption [5]. But it is often not effective or economical. For instance, using chemical precipitation method for the removal of $\mathrm{Zn}(\mathrm{II})$, that uses alkaline solution to raise the $\mathrm{pH}$ of the solution, to allow the formation of heavy metal hydroxide $\left(\mathrm{ZnOH}_{2}\right)$ precipitate 
followed by filtration, was effective. But the resultant heavy metal hydroxide sludge is classified as a hazardous waste, which needs further treatment before disposal [6].

Activated carbon has been widely used to remove heavy metals from wastewater. However, activated carbon is a very expensive material. Thus, this kind of treatment may be unaffordable for small-scale industries. The high costs of activated carbon have inspired many researchers to look for alternative development suitable and low-cost adsorbent. Trends in new materials highlight the importance of using wastes and industrial waste as production adsorbent materials [7]. Several studies have been made significant contributions in this area. Utilizing a number of adsorbent materials from agricultural waste such as, sawdust and neem bark [8], [9], rice husk [10], Durio zibethinus seed [11], shell and seed of Kelengkeng fruits [12], stem tree of Soybean [13], Jengkol's husk [14], Eleocharis dulcis Fibers [15], Arenga pinnata fruit shell [16], and from industrial sludge such as from from WWTP (waste water treatment plant) sludge [17]-[20], metal industry sludge [21], palm oil mill sludge [22], yarn factory sludge [23], dairy filtering station sludge [24], drinking water treatment sludge [25]-[27], to minimize metal ions was reported.

Waste activated sludge of crumb rubber industry (CRIWAS) is discarded as waste from crumb rubber industry wastewater treatment processing which presents a significant disposal problem [28]. Efforts have been created to recycle the waste product by using it as an adsorbent. It is expected that the sludge, having a significant organic carbon content, also has a substantial capacity to adsorb heavy metals. Other elements content of the sludge, such as silica, alumina, and calcium can also contribute to heavy metal uptake [28], [29]. The use of CRI-WAS as the adsorbent is still widely unexplored in much of published literature. The latest has been reported for metal ion $\mathrm{Cr}(\mathrm{VI})$ adsorption with $\mathrm{NaOH}$ and H3PO4 activator and for metal ion Cd(II) [28]-[30]. In This present work, three different materials with adsorbent properties were produced from CRI-WAS. The main objective of this study was to investigate the feasibility of using these CRI-WAS based adsorbents for the removal of the metal ions $\mathrm{Zn}$ (II) from aqueous solutions with respect to the variation of adsorbent type, $\mathrm{pH}$, contact time and dose. The evaluation of its adsorption capacities was under batch experiments.

\section{MATERIAL AND METHOD}

\section{A. CRI-WAS Adsorbent Material}

Waste activated sludge of Crumb rubber industry (CRIWAS) was obtained from Kilang Lima Gunung Limited liability company of crumb rubber Industry in Padang city Indonesia. In this plant, where wastewater undergoes an activated sludge biological treatment, produce an excess sludge from the final clarifier. An excess sludge was collected and dried. Dried sludge was used as starting material to produce three different kind adsorbents.

\section{B. Preparation of the CRI-WAS Adsorbent Material}

The raw sludge as material for adsorbents was firstly sundried for three days and then dried in an oven (Memmert
UNB 300) at $70^{\circ} \mathrm{C}$ for approximately 5 hours. Then, ground and passed it through 40-60 mesh sieves by using test siever merk Retsch 5657 Haun W. Germany. This material will be the first type of adsorbent in this study and was named PS (Pure Sludge). The pure sludge soaked in $0.01 \mathrm{M}$ nitric acid (HNO3) for 2 hours, to remove impurities, washed and rinsed with double distillate water until initial solution $\mathrm{pH}$, dried again and it was named WS (Washed Sludge). Using the same initial pure sludge as above, a carbonaceous char, which was named P600, as the third type adsorbent, was also produced by pyrolysis the pure sludge in the pyrolysis equipment at temperature $600^{\circ} \mathrm{C}$.

\section{Chemicals}

All the necessary chemicals used in the study were of analytical grade. $\mathrm{Zn}$ (II) solutions were prepared by diluting a stock solution with double distilled water. The $\mathrm{pH}$ of each solution was adjusted to the desired value by adding diluted $\mathrm{H}_{2} \mathrm{SO}_{4}$ or $\mathrm{NaOH}$, with the aid of a $\mathrm{pH}$ meter (Hanna HI 2213).

\section{Experimental}

The necessary amount of CRI-WAS adsorbent was taken in a $100 \mathrm{~mL}$ stopper conical flask containing $20 \mathrm{~mL}$ of the desired concentration of the standard solution. Then were shaken for the desired contact time in an electrically Adjustable Reciprocating Orbital Shaker (AROS)-160TM at $180 \mathrm{rpm}$. The samples were withdrawn from the flasks through Whatman 42 filter paper, and the filtrate was analysed for remaining metal concentration in the sample using Atomic Absorption Spectrophotometer GBC 932 AA. The amount of $\mathrm{Zn}$ (II) adsorbed per unit mass of the adsorbent was evaluated by using the same following equation:

$$
\mathrm{qe}=\frac{(\mathrm{C} 0-\mathrm{Ce}) \mathrm{V}}{\mathrm{m}}
$$

where qe is the amount of $\mathrm{Zn}(\mathrm{II})$ ions adsorbed per unit mass of the adsorbent $(\mathrm{mg} / \mathrm{g}), \mathrm{V}$ is the volume of the solution $(\mathrm{L})$, $\mathrm{m}$ is the mass of the adsorbent $(\mathrm{g}) ; \mathrm{C} 0$ and $\mathrm{Ce}$ are the concentration of $\mathrm{Zn}(\mathrm{II})$ ions in the initial solution and in aqueous solution after adsorption for minute in $\mathrm{mg} / \mathrm{L}$, respectively.

The data were analysed by analysis of variance (ANOVA) and a further test Duncan's New Multiple Range Test (DNMRT) at the 5\% significance level.

\section{E. Characterization of CRI WAS Adsorbent}

PS, WS and P600 CRI-WAS adsorbents characterization performed on samples before and after the adsorption process. Elemental composition was determined by XRF (Xray fluorescence spectrometer) merk PANalytical Epsilon3. Available surface functional groups were qualitatively determined by Fourier Transform Infrared (FTIR) spectroscopy (SpectrumTM One Spectrometer, Perkin Elmer). Surface morphology of adsorbents was obtained by scanning electron microscopy coupled with EDX (SEMEDX, Hitachi model S-3400N). Surface areas (BET (Brunaeur-Emmet-Teller) by Surface Area Analyzer and Pore Size Analyser Quadrasorb SI. 


\section{RESULT AND DISCUSSION}

\section{A. Characterization of CRI WAS Adsorbent}

Characterization of adsorbent is crucial in understanding the elemental composition that may influence the adsorptive ability of adsorbent (Table 1 and 2). The rate value of EDX on CRI-WAS (PS) and its adsorbents derivatives, namely WS and P600 before and after $\mathrm{Zn}(\mathrm{II})$ adsorption process can be seen in Table 1. EDX value was taken randomly at three different point pores in each adsorbent. The elemental composition in oxide form on each of the adsorbent that characterizes by XRF can be seen in Table 2. Both of Table show that all type of CRI-WAS adsorbent having high $\mathrm{Al}_{2} \mathrm{O}_{3}$, $\mathrm{SiO}_{2}, \mathrm{CaO}, \mathrm{C}, \mathrm{O}, \mathrm{Si}$, and $\mathrm{Ca}$ content. Obviously, all element content decreased after washing and pyrolysis except for, $\mathrm{CaO}, \mathrm{FeO}, \mathrm{MgO}$ and $\mathrm{C}$ content at $\mathrm{P} 600 . \mathrm{Al}_{2} \mathrm{O}_{3}, \mathrm{SiO}_{2}$, and $\mathrm{CaO}$ are the dominant oxide chemical compositions in sludge [27]. Most of the elements were leached when soaking and washing under acidic conditions [22]. Also, most of the volatile organic burned-off when pyrolysis [19].

When comparing before and after $\mathrm{Zn}$ (II) adsorption process, it can be seen that $\mathrm{Al}_{2} \mathrm{O} 3, \mathrm{SiO}_{2}, \mathrm{CaO}$ and $\mathrm{Fe}_{2} \mathrm{O}_{3}$ content of the three adsorbents decreased after $\mathrm{Zn}$ (II) adsorption process except for $\mathrm{ZnO}$ (Table 2). So were the $\mathrm{C}$, $\mathrm{O}, \mathrm{Al}, \mathrm{Si}$ and $\mathrm{Ca}$ content except for $\mathrm{Zn}(\mathrm{II})$ (Table 1). From Table 2 also show that $\mathrm{Zn}$ increase after adsorption process. On the other hand, from Table $1 \mathrm{Zn}$ (II) is detected only after adsorption process. It indicates that all of these elements contribute to increasing the $\mathrm{Zn}$ (II) adsorption capacity.

The surface morphology and the higher silica and alumina content in CRI-WAS adsorbent before and after $\mathrm{Zn}(\mathrm{II})$ adsorption process can also be seen from SEM image and EDX spectra (Fig. 5 (A)(B) and Fig. 6 (A)(B)). From SEM image can be observed that the development of surface pores of P600 looks more than PS, and WS (Fig. 5(A)). It appears that the adsorbent exhibits an irregular gap arrangement and a gap that confirms amorphous and heterogeneous structures. It also appears that P600 displays a honeycomb-like morphology developed with multiple micro-holes on the surface. This is expected to potentially place trapped and adsorbed pollutants or metal ions. From EDX spectra shows that $\mathrm{Si}$ and $\mathrm{Al}$ were a dominant elemental in all type of CRIWAS adsorbents before Zn(II) loaded (Fig. 5 (B)). On the other hand, after Zn(II) loaded (Fig. 6 B), Zn(II) appeared in all type of CRI-WAS adsorbent.

CRI-WAS adsorbent characterization is also done with FTIR (Fig. 7). Fig. 7 shows that the PS spectrum is similar to the WS spectrum in the case of peak. Both of the spectra exhibit a prominent 3 peaks centered at $3301-3316 \mathrm{~cm}^{-1}$, $1633 \mathrm{~cm}^{-1}$, and $1030 \mathrm{~cm}^{-1}$. The first peak can be attributed to the stretching vibration mode of the $\mathrm{O}-\mathrm{H}$ bond in surface hydroxyl groups or adsorbed water molecules. The peak at $1633 \mathrm{~cm}-1$ can be attributed to the stretching vibration mode of $\mathrm{C}=\mathrm{O}$ bond or $\mathrm{C}=\mathrm{C}$ bond and a very sharp peak was observed at $1030 \mathrm{~cm}^{-1}$, indicating the presence of $\mathrm{Si}-\mathrm{O}-\mathrm{Si}$ or $\mathrm{Si}-\mathrm{O}-\mathrm{C}$ bond. A small peak found at $2223 \mathrm{~cm}^{-1}$ corresponded to the stretching vibration mode of $\mathrm{C} \equiv \mathrm{N}$ or $\mathrm{C} \equiv \mathrm{N}$ bond. Another small peak was also found at $679 \mathrm{~cm}^{-1}-695 \mathrm{~cm}^{-1}$ and was attributed to the symmetric bending vibration mode of the $\mathrm{Si}-\mathrm{O}$ bond within $\mathrm{SiO} 4$ group [20], [26].
Differ to PS and WS, P600 has a broad peak at $2575 \mathrm{~cm}^{-1}$ $3346 \mathrm{~cm}^{-1}$ which are associated with the presence of water (hydroxyl groups). It also has another 5 prominent peaks in its spectra. They are at $2087 \mathrm{~cm}^{-1} .1886 \mathrm{~cm}^{-1}, 1409 \mathrm{~cm}^{-1}$, $1045 \mathrm{~cm}^{-1}$, and $858 \mathrm{~cm}^{-1}$. At the peak of $2087 \mathrm{~cm}^{-1}$ indicates the presence of double bonds or carboxyl metal complex $(\mathrm{C}$ $=\mathrm{O}-\mathrm{M}$ ) [20]. The $1400 \mathrm{~cm}^{-1}$ region gives some idea of the relative abundance of $\mathrm{CH}_{2}$ and $\mathrm{CH}_{3}$ groupings. The stronger peak at $1045 \mathrm{~cm}^{-1}$, also associated with $\mathrm{Si}-\mathrm{O}-\mathrm{Si}$ structures, indicates the presence of more silicate functional groups [26], [31]. At $1886 \mathrm{~cm}^{-1}$ and $858 \mathrm{~cm}^{-1}$ exhibit $\mathrm{C}-\mathrm{H}$ vibrations. The $\mathrm{Si}-\mathrm{O}$ bond was found in all sample spectra and demonstrated the formation of silicate.

TABLE I

VALUE EDX OF PS, WS P600 CRI-WAS TYPE OF ADSORBENT BEFORE AND AFTER ZN(II) ADSORPTION PROCESS

\begin{tabular}{|c|c|c|c|c|c|c|}
\hline \multirow{2}{*}{ Element } & \multicolumn{2}{|c|}{ Before Zn(II) Adsorption } & \multicolumn{2}{|c|}{ After Zn(II) } & \multicolumn{2}{l|}{ Adsorption } \\
\cline { 2 - 7 } & PS & WS & P 600 & PS & WS & P 600 \\
\hline $\mathrm{C}$ & 43.46 & 45.86 & 53.65 & 24.57 & 23.4 & 10.65 \\
\hline $\mathrm{O}$ & 43.16 & 45.99 & 22.37 & 37.27 & 33.18 & 21.69 \\
\hline $\mathrm{Al}$ & 3.67 & 1.16 & 2.89 & 1.02 & 1.75 & 1.37 \\
\hline $\mathrm{Si}$ & 5.55 & 2.8 & 5.39 & 1.47 & 3.73 & 0.02 \\
\hline $\mathrm{Ca}$ & 3.33 & 3.25 & 13.96 & 1.42 & 1.31 & 0 \\
\hline $\mathrm{K}$ & 0.83 & 0.94 & 1.74 & 0 & 0.72 & 0.04 \\
\hline $\mathrm{Cd}$ & 0 & 0 & 0 & 0 & 0.00 & 0.00 \\
\hline $\mathrm{Zn}$ & 0 & 0 & 0 & 34.25 & 35.91 & 66.23 \\
\hline
\end{tabular}

TABLE II

XRF ANALYSIS OF PS, WS P600 CRI-WAS TYPE ADSORBENT BEFORE AND AFTER ZN(II) ADSORPTION PROCESS

\begin{tabular}{|c|l|l|l|l|l|l|}
\hline \multirow{2}{*}{$\begin{array}{c}\text { Meta } \\
\text { l ion } \\
\text { Oxide }\end{array}$} & \multicolumn{2}{|l|}{ Before $\mathrm{Zn}(\mathbf{I I})$ adsorption } & \multicolumn{2}{l|}{ After Zn(II) adsorption } \\
\cline { 2 - 7 } & PS & WS & P 600 & PS & WS & P 600 \\
\hline $\mathrm{A} 2 \mathrm{O} 3$ & 16.076 & 14.613 & 9.64 & 15.778 & 14.038 & 8.352 \\
\hline $\mathrm{SiO} 2$ & 63.203 & 59.089 & 18.558 & 36.68 & 47.788 & 14.613 \\
\hline $\mathrm{K} 2 \mathrm{O}$ & 0.757 & 0.462 & 1.123 & 0.561 & 0.509 & 0.953 \\
\hline $\mathrm{CaO}$ & 18.411 & 6.656 & 40.016 & 11.914 & 5.185 & 27.364 \\
\hline $\mathrm{Fe} 2 \mathrm{O} 3$ & 3.168 & 2.733 & 9.423 & 4.403 & 3.514 & 9.315 \\
\hline $\mathrm{NiO}$ & 0 & 0.005 & 0.016 & 0 & 0.002 & 0.013 \\
\hline $\mathrm{CuO}$ & 0.012 & 0.012 & 0.068 & 0.027 & 0.02 & 0.054 \\
\hline $\mathrm{ZnO}$ & 0.048 & 0.035 & 0.269 & 3.286 & 2.305 & 9.175 \\
\hline $\mathrm{CdO}$ & 0 & 0 & 0 & 0 & 0 & 0 \\
\hline $\mathrm{MgO}$ & 0.022 & 0.022 & 6.293 & 0.012 & 0.01 & 3.504 \\
\hline
\end{tabular}

TABLE IIII

PROPERTIES OF PS, WS AND P600 CRI-WAS TYPE OF ADSORBENT

\begin{tabular}{|c|r|r|}
\hline $\begin{array}{c}\text { Type of CRI-WAS } \\
\text { Adsorbent }\end{array}$ & sBET $\left(\mathbf{m}^{\mathbf{2}} / \mathbf{g}\right)$ & \multicolumn{1}{|c|}{$\mathbf{R}^{\mathbf{2}}$} \\
\hline PS & 1,381 & 0.9841 \\
\hline WS & 2,516 & 0.9884 \\
\hline P600 & 52,180 & 0.9989 \\
\hline
\end{tabular}




\section{B. Effect of Solution $\mathrm{pH}$}

The Solution $\mathrm{pH}$ influences the surface active site distribution on metal oxides and the surface hydroxyl group provides the ability to bind metal ions. The acidity of the medium affects the competition of hydrogen ions and metal ions on the surface of the adsorbent site [32]. The adsorption capacity of the three types of adsorbents was analyzed at a $\mathrm{pH}$ range from 1 to 7 (Fig. 1). On Fig. 1 show that the maximum percentage removal of $\mathrm{Zn}(\mathrm{II})$ by CRI-WAS adsorbents were obtained in the $\mathrm{pH} 5$ for all types of adsorbents which are $89.8 \%, 90.8 \%$ and $99 \%$ for PS, WS, and P600 CRI-WAS respectively. Thus, $\mathrm{pH} 5$ was considered to be the optimum $\mathrm{pH}$ for further studies. Similar results have been reported for other types of adsorbents [5], [8], [31]. The effect of $\mathrm{pH}$ can be explained considering the surface charge of the adsorbent material. At low $\mathrm{pH}$, due to high positive charge density due to protons on the surface sites, electrostatic repulsion will be high during uptake of metal ions resulting in lower removal efficiency. With increasing $\mathrm{pH}$, electrostatic repulsion decreases due to the reduction of positive charge density on the sorption sites thus resulting in an enhancement of metal adsorption [8].

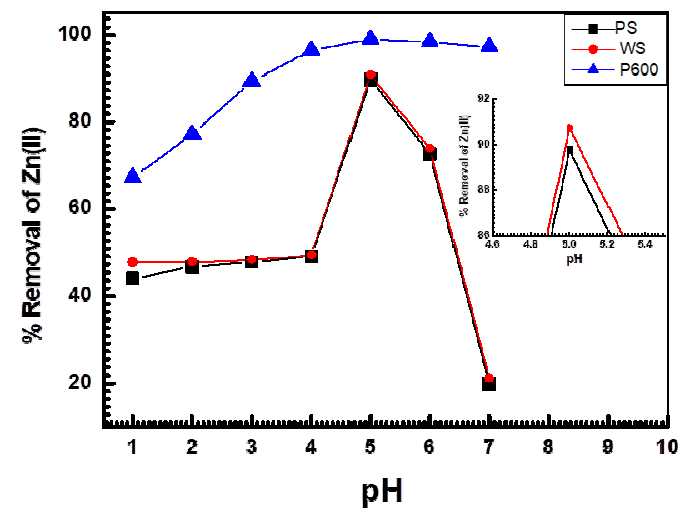

Fig. 1 Effect pH of Zn(II) adsorption onto PS, WS, P600 CRI-WAS types of adsorbent

\section{Effect of Contact Time}

The effect of contact time on removal of $\mathrm{Zn}$ (II) by a different type of adsorbents was shown in Fig. 2. The percent removal of $\mathrm{Zn}(\mathrm{II})$ increased sharply during the first 30 minutes of metal-adsorbent contact on the PS and WS type adsorbents, and for P600, the percent removal directly high increased for the first e few minute until 30 minutes, after that the percent removal decreasing, then remind constantly after $60 \mathrm{~min}$. It is obvious that increase in contact time enhanced the percent removal of $\mathrm{Zn}$ (II) significantly. This phenomenon could be attributed to the instantaneous utilization of the most readily available adsorbing sites on the adsorbent surface [17].

\section{Effect of Dose}

The adsorbent dose also affects the adsorption capacity of the metal ions. The effect of adsorbent dosage on adsorption of $\mathrm{Zn}$ (II) was studied using different dosage in the range, $0.1-1.0 \mathrm{~g}^{2} \mathrm{ml}^{-1}$ (Fig. 3 and Fig. 4). Results showed that the adsorption efficiency is highly dependent on the quantity of adsorbent used. Fig. 3 shows that with the dose of adsorbent increase from 0.1-1.0 g, the percent removal of $\mathrm{Zn}(\mathrm{II})$ increased from $54.5 \%-87.9 \%, 58.5 \%-90.4 \%$ and $80.2 \%$ -
96.7\% for PS, WS, and P600 respectively. On the other hand, From Fig. 4 show that, with the dose adsorbent increase from $0.1-1.0 \mathrm{~g}$, the adsorption capacity of $\mathrm{Zn}$ (II) decreased from $10.2-1.6 \mathrm{mg} / \mathrm{g}, 11-1.7 \mathrm{mg} / \mathrm{g}$, and $64.2-7.8 \mathrm{mg} / \mathrm{g}$ for PS, WS, and P600 respectively. It can be explained that as the adsorbent dose was increased, the adsorption equilibrium was attained in a shorter time and higher removal efficiency was achieved due to the increase in a number of adsorptive sites. On the other hand, the adsorption capacity, considered as the number of metal ions adsorbed per gram of adsorbents, decreased in increasing the adsorbent dose. An increase in adsorbent dose resulted in a reduced proportion of metal ions amount in solution with respect to the number of active sites on the adsorbent, which may lead to a change in adsorption equilibrium. Furthermore, when the adsorbent dose increased, the unsaturation of active sites on surface occurred, and therefore, the adsorption capacity decreased [18].

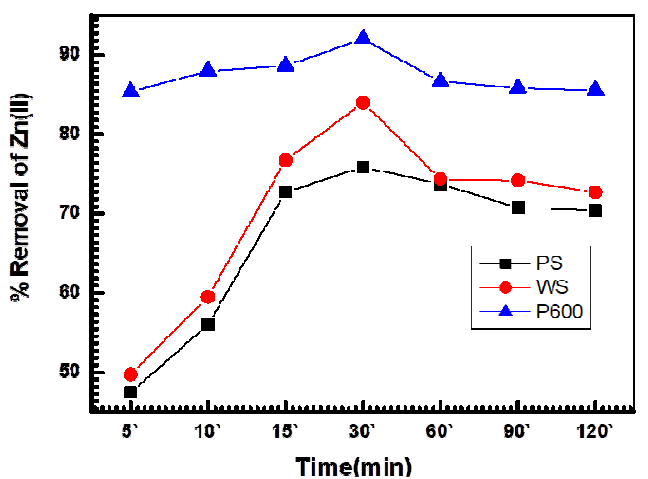

Fig. 2 Effect of contact time of Zn(II) onto PS, WS, P600 CRI-WAS types of adsorbent

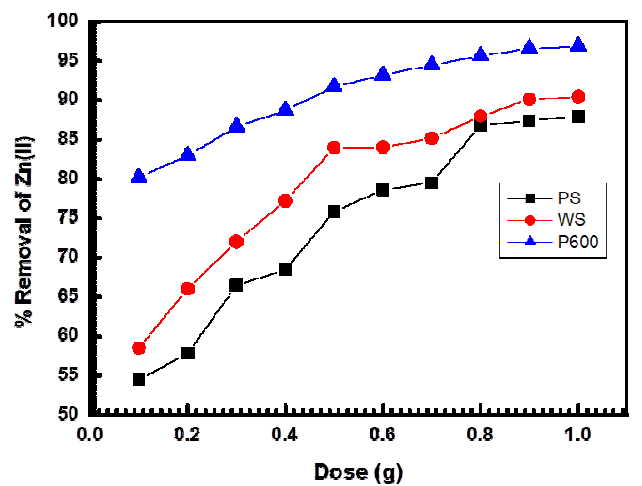

Fig. 3 Effect of adsorbent dose on the percent removal of $\mathrm{Zn}$ (II) onto PS, WS, P600 CRI-WAS types of adsorbent

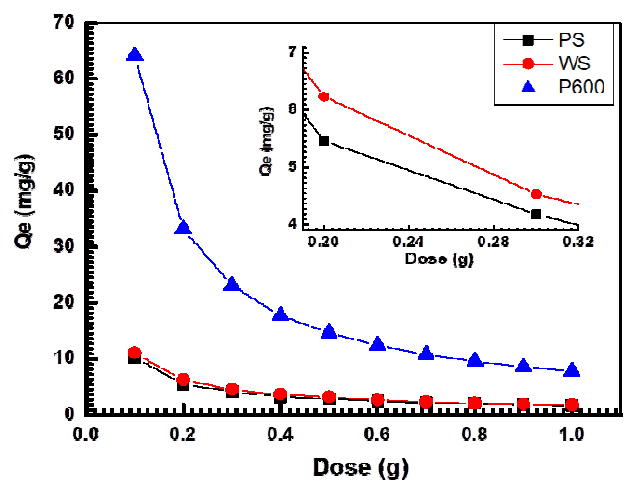

Fig. 4 Effect dose to the adsorption capacity of Zn(II) onto PS, WS, P600 CRI-WAS types of adsorbent 
From all aspects studied, reveal that the adsorption capacity P600>WS and WS $>$ PS. After data were analyzed by analysis of variance (ANOVA) and a further test Duncan's New Multiple Range Test (DNMRT) at the 5\% significance level shown that WS and PS was not significantly different, but the adsorbent type P600 CRIWAS has more significant effected on the removal of $\mathrm{Zn}$ (II) than PS and WS. For the effect of contact time, P600 reach maximum $92 \%$ percentage of $\mathrm{Zn}$ (II) removal that higher than PS (75.8\%) and WS (84\%). The effect of the dose also performs the same trend which are $87.9 \%, 90.4 \%$, and $96.7 \%$ and with adsorption capacity $10.2 \mathrm{mg} / \mathrm{g}, 11,0 \mathrm{mg} / \mathrm{g}$, and $64.2 \mathrm{mg} / \mathrm{g}$ for PS,WS, and P600 respectively. A similar result also is shown by the effect of solution $\mathrm{pH}$, which are $89.8 \%, 90.8 \%$ and $99 \%$ for PS, WS and P600 CRI-WAS respectively. It can be explained as seen in Table 3 that P600 has higher sBET, and beside content silica, it also has more carbon content than WS and PS (Table 1). All of these parameters contribute to increasing the adsorption capacity of CRI-WAS adsorbents of P600 type. The highest adsorption capacity on P600 also can be explained that P600 was produced by pyrolysis process at $600^{\circ} \mathrm{C}$. Pyrolysis process will help to remove surface impurities, and leachable minerals and pyrolysis temperature could be promoted the development of the specific surface area, while very high temperatures could destroy the pore structure and reduce the specific surface area. But generally, development of the specific surface area could be reached after paralytic processes (at temperatures from 400 to $800^{\circ} \mathrm{C}$ ) [19]. The larger the surface area, the higher the adsorption capacity. Higher adsorption capacity by activated sludge adsorbent can be attributed to its BET surface area and high microspore volume [7]. Adsorption Zn(II) by sludge may be attributed due to the combined effect of silica, metal oxides and carbon present in it as major constituents [8]

\section{E. Adsorption Isotherm Analysis}

In order to gain a better understanding of sorption mechanisms and evaluate the sorption performance, the experimental data for $\mathrm{Zn}$ (II) adsorption onto CRI-WAS adsorbent was analyzed using the Langmuir adsorption isotherm model. The adsorption equilibrium data are conveniently represented by adsorption isotherms, which correspond to the relationship between the mass of $\mathrm{Zn}$ (II) per unit mass of adsorbent qe and the solute concentration of the solution at equilibrium $\mathrm{Ce}$ [21], [24]. Figs. 7, 8 and 9 show a plot of linear Langmuir equation as $1 /$ qe versus $1 / \mathrm{Ce}$ of PS, WS and P600 CRI-WAS types of adsorbents. The plots are linear with good correlation. The sorption isotherms fit Langmuir model due to the larger correlation coefficient (R2) which are $0.9841,0.9884$ and 0.9989 for PS, WS and P600 CRI-WAS types of adsorbent respectively. It is suggesting that $\mathrm{Zn}(\mathrm{II})$ sorption on CRI-WAS adsorbent is monolayer chemical sorption process.

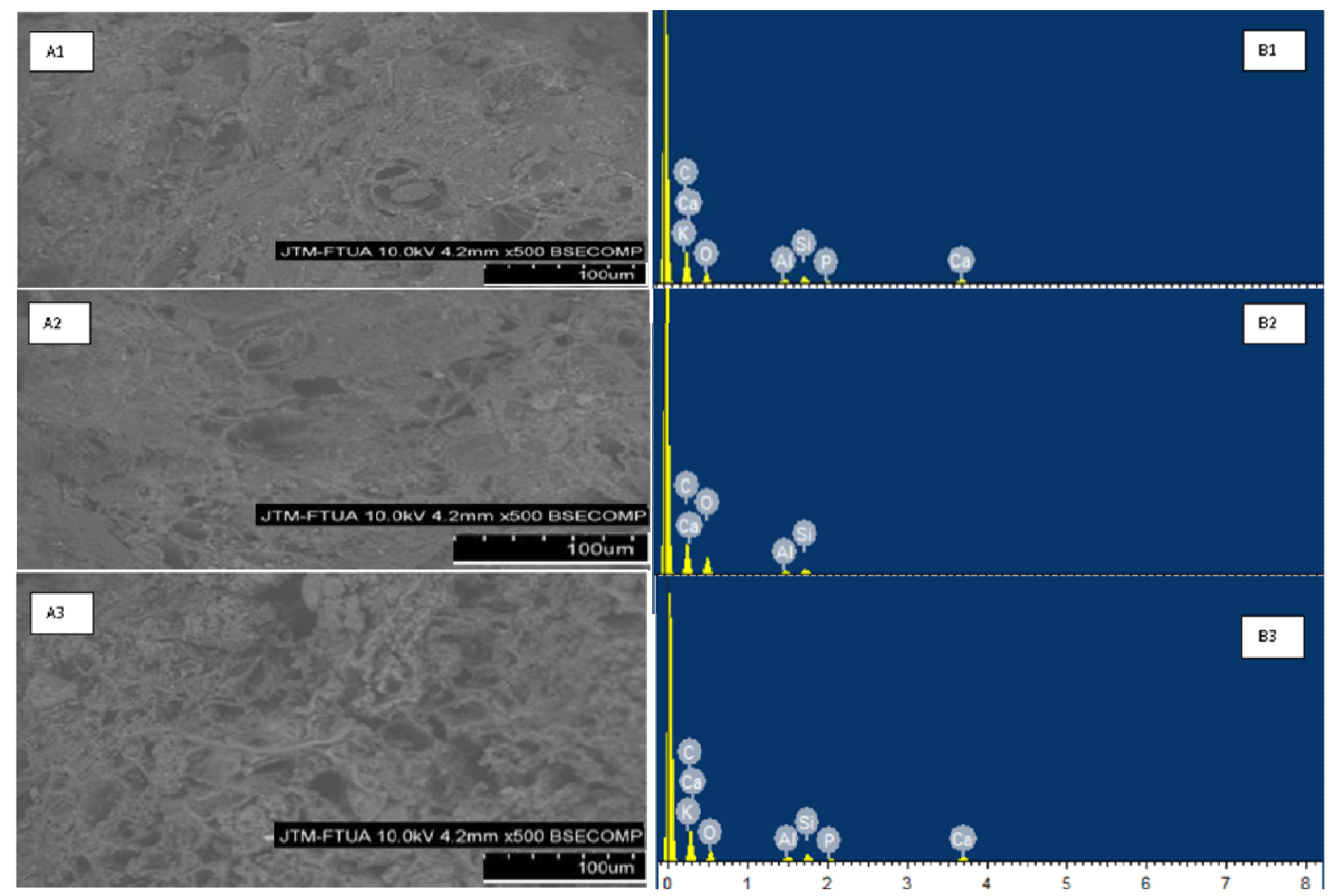

Fig. 5 SEM-EDX photos of PS (A1, B1), WS (A2, B2) and P600 CRI-WAS (A3,B3) types of adsorbent before Zn(II) adsorption process by 500 times of magnification 


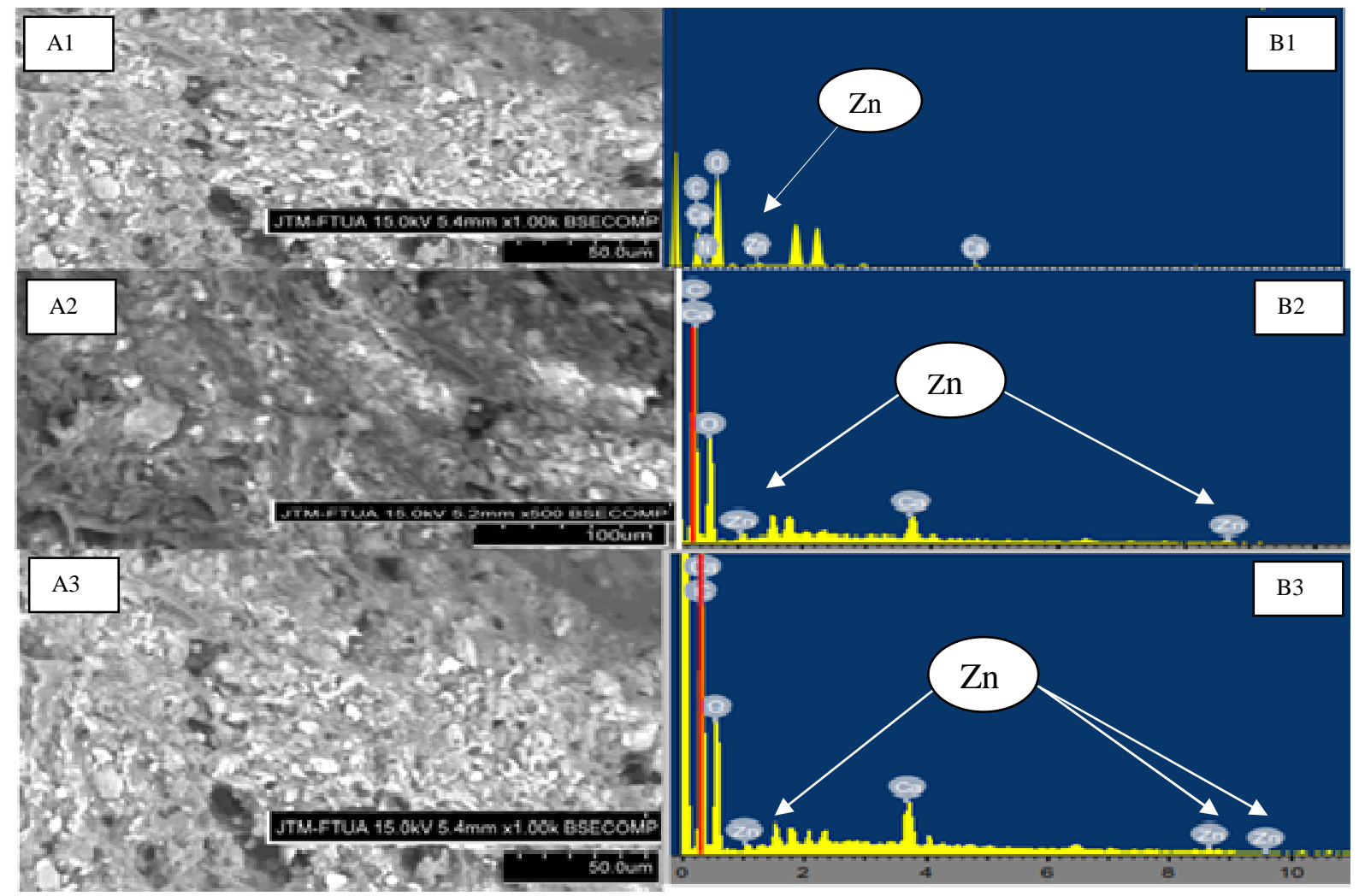

Fig. 6 SEM-EDX photos of PS (A1, B1), WS (A2, B2) and P600 (A3,B3) CRI-WAS types of adsorbent after Zn(II) adsorption process by 500-10,000 times of magnification

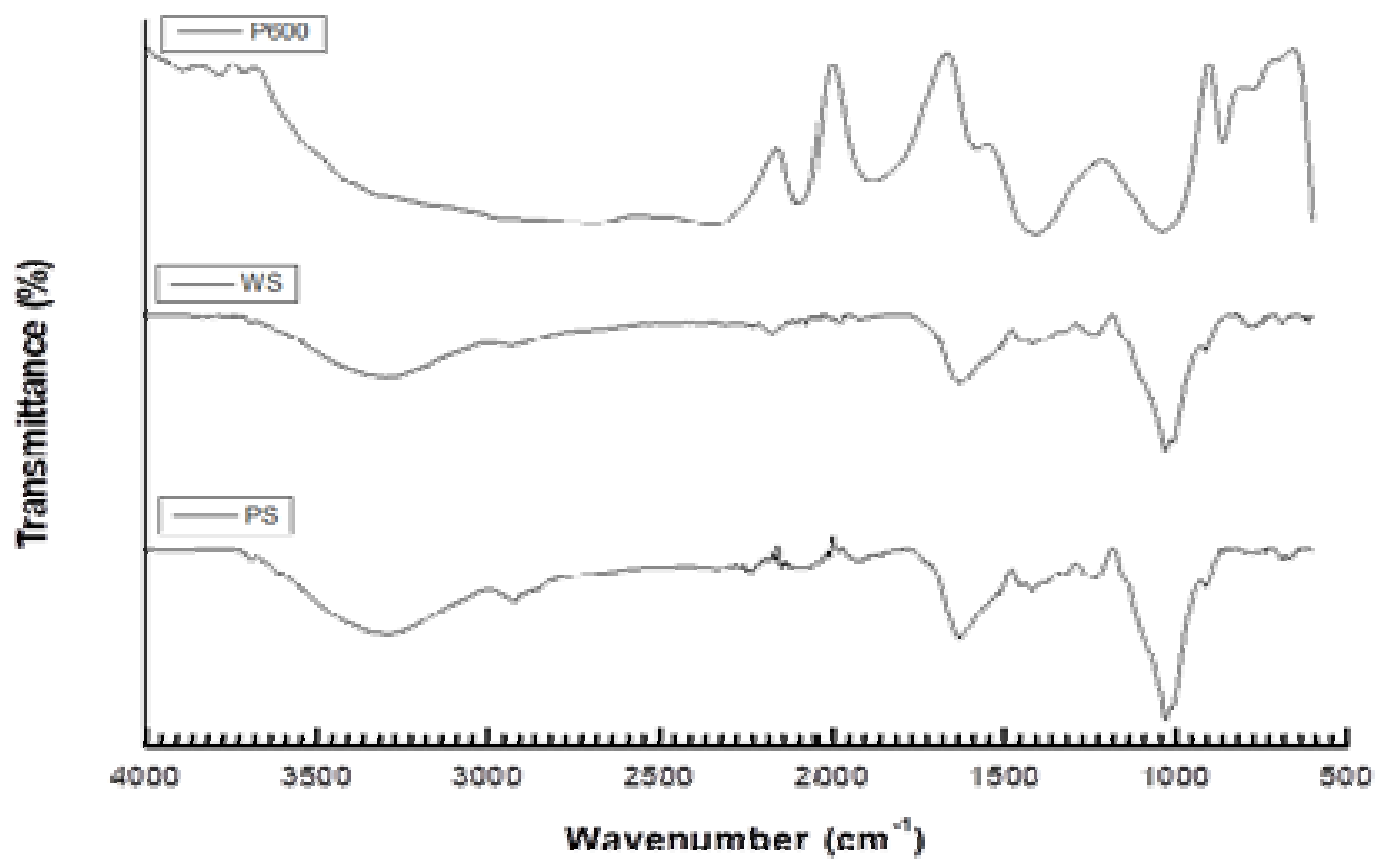

Fig. 7 FTIR Spectra of PS, WS and P600 CRI-WAS types of adsorbent before Zn(II) adsorption process 


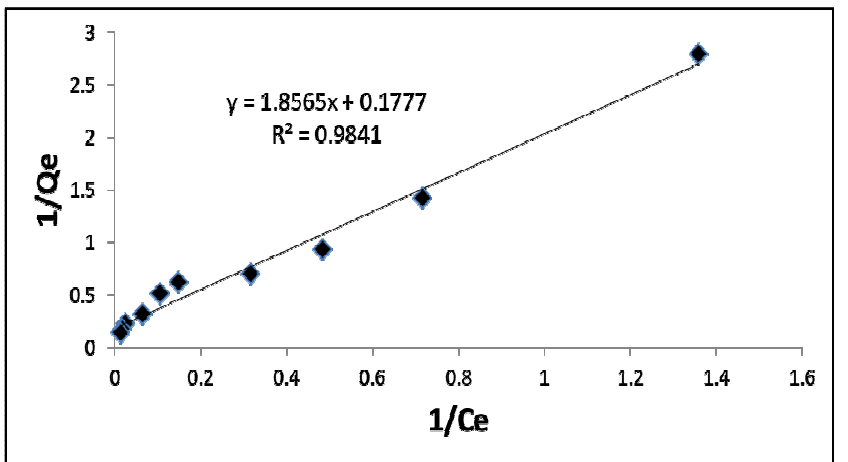

Fig. 8 Isotherm Adsorption of $\mathrm{Zn}$ (II) onto PS CRI-WAS types of adsorbent

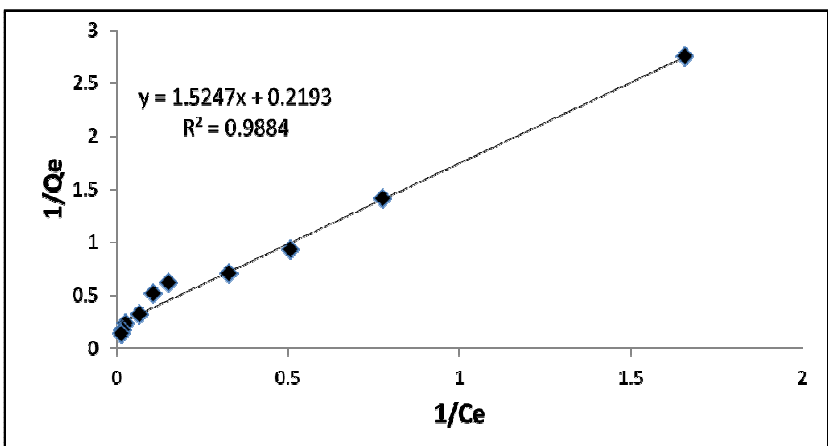

Fig. 9 Isotherm Adsorption of Zn(II) onto WS CRI-WAS types of adsorbent

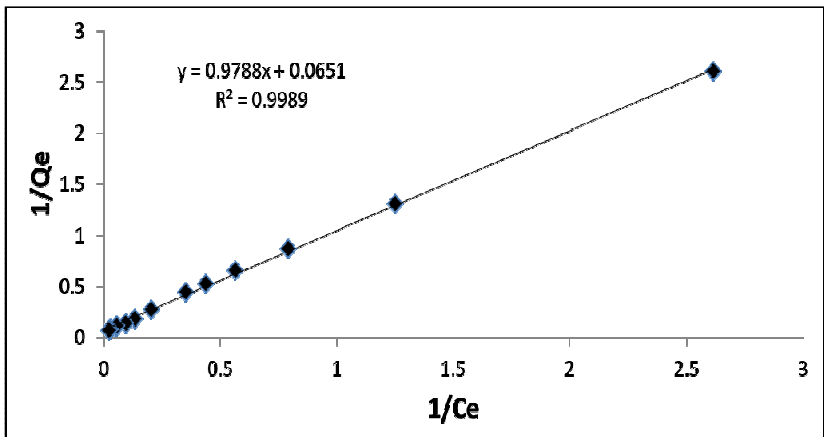

Fig. 10 Isotherm Adsorption of $\mathrm{Zn}$ (II) onto P600 CRI-WAS types of adsorbent

\section{CONCLUSION}

Three types of adsorbents prepared from the waste activated sludge of crumb rubber industry (CRI-WAS) able to remove of $\mathrm{Zn}(\mathrm{II})$ from aqueous solutions. The adsorption capacity where P600 (pyrolysis at $600^{\circ} \mathrm{C}$ ) > WS (washing sludge) > PS (pure sludge). They are $64.169 \mathrm{mg} \mathrm{g}^{-1}, 11.042$ $\mathrm{mg} \mathrm{g}^{-1}$, and $10.276 \mathrm{mg} \mathrm{g}^{-1}$ for P600, WS, and PS CRI-WAS types of adsorbent respectively. All types of adsorbent exhibited good sorption potential at $\mathrm{pH}$ 5.0.

\section{NOMENCLURATE}

q

initial concentration

$\mathrm{Ci}$ equilibrium concentration

$V \quad$ volume of testing solution

$m$ mass of adsorbent

$$
\begin{aligned}
& \mathrm{mg} \mathrm{g}^{-1} \\
& \mathrm{mg} \mathrm{L}^{-1} \\
& \mathrm{mg} \mathrm{L}^{-1} \\
& \mathrm{~L} \\
& \mathrm{~g}
\end{aligned}
$$

Ministry of Industry of The Republic of Indonesia for the financial support, and also to Institute for Research and Standardization of Industry Padang for all research facilities.

\section{REFERENCE}

[1] F. Fu and Q. Wang, "Removal of heavy metal ions from wastewaters: A review," J. Environ. Manage., vol. 92, no. 3, pp. 407-418, 2011.

[2] N. Oyaro, O. Juddy, E. N. M. Murago, and E. Gitonga, "The contents of $\mathrm{Pb}, \mathrm{Cu}, \mathrm{Zn}$ and $\mathrm{Cd}$ in meat in Nairobi, Kenya," J. Food, Agric. Environ., vol. 5, pp. 119-121, 2007.

[3] WHO, Guidelines for Drinking Water Quality, 3 rd. Genewa: Worid Health Organization, 2004.

[4] KLH, Peraturan Menteri Lingkungan Hidup Republik Indonesia Nomor 5 Tahun 2014 Tentang Baku Mutu Air Limbah, no. 96. Jakarta: Kementerian Lingkungan Hidup, 2014.

[5] L. Ramrakhiani, S. Ghosh, S. Sarkar, and S. Majumdar, "Heavy meta biosorption in multi component system on dried activated sludge: Investigation of adsorption mechanism by surface characterization," Mater. Today Proc., vol. 3, no. 10, pp. 3538-3552, 2016.

[6] N. Gupta, S. S. Amritphale, and N. Chandra, "Removal of Zn (II) from aqueous solution by using hybrid precursor of silicon and carbon," Bioresour. Technol., vol. 101, no. 10, pp. 3355-3362, 2010.

[7] F. Rozada, M. Otero, a. Morán, and a. I. García, "Adsorption of heavy metals onto sewage sludge-derived materials," Bioresour. Technol., vol. 99, pp. 6332-6338, 2008.

[8] A. K. Bhattacharya, S. N. Mandal, and S. K. Das, "Adsorption of Zn(II) from aqueous solution by using different adsorbents," Chem. Eng. J., vol. 123 , no. 1-2, pp. 43-51, 2006.

[9] T. K. Naiya, P. Chowdhury, A. K. Bhattacharya, and S. K. Das, "Saw dust and neem bark as low-cost natural biosorbent for adsorptive removal of $\mathrm{Zn}$ (II) and $\mathrm{Cd}(\mathrm{II})$ ions from aqueous solutions," Chem. Eng. J., vol. 148 , pp. 68-79, 2009.

[10] M. Kasman, S. Ibrahim, and S. Sy, "Rice Husk Packed Bed Column Reactor to Remove Cadmium from Landfill Leachate," J. Litbang Ind. vol. 4, no. 1, pp. 9-17, 2014.

[11] I. Lestari, S. Sy, D. Kurniawati, A. Alif, R. Zein, and H. Aziz, "Effect of $\mathrm{pH}$ on the biosorption of heavy metal by alginate immobilized durian (Durio zibethinus) seed," Der Pharma Chem., vol. 8, no. 5, pp. 294-300, 2016.

[12] K. Desi, I. Lestari, S. Sy, H. Aziz, Z. Chaidir, and R. Zein, "Removal of $\mathrm{Cu}$ ( II ) from aqueous solutions using shell and seed of kelengkengfruits ( Euphoria longan Lour )," Der Pharma Chem., vol. 8, no. 14, pp. 149-154, 2016.

[13] Harmiwati, S. Salmariza, D. Kurniawati, I. Lestari, Z. Chaidir, R Desmiarti, and R. Zein, "Biosorption of Pb (II) And Zn (II) Metal Ions from Aqueous Solutions by Stem Tree of Soybean Using Continuous,' ARPN J. Eng. Appl. Sci., vol. 12, no. 18, pp. 5258-5262, 2017.

[14] F. Azima, N. Nazir, and N. P. Sari, "The making and characterization of Husk Jengkol'S activated carbon as adsorbent," Int. J. Adv. Sci. Eng. Inf. Technol., vol. 7, no. 3, pp. 916-921, 2017.

[15] C. Irawan, I. F. Nata, M. D. Putra, M. Elma, and K. F. Hanisa, "Biocomposite Materials of Eleocharis dulcis Fibers with Iron ( III ) Nanoparticles and Its Potential for Sasirangan Textile Wastewater Treatment," Int. J. Adv. Sci. Eng. Inf. Technol., vol. 7, no. 4, pp. 12341240, 2017

[16] R. Zein, D. A. Hidayat, M. Elfia, N. Nazarudin, and E. Munaf, "Sugar palm Arenga pinnata Merr (Magnoliophyta) fruit shell as biomaterial to remove $\mathrm{Cr}(\mathrm{III}), \mathrm{Cr}(\mathrm{VI}), \mathrm{Cd}(\mathrm{II})$ and $\mathrm{Zn}(\mathrm{II})$ from aqueous solution," $J$. Water Supply Res. Technol., vol. 63, no. 7, p. 553, 2014.

[17] C. Yang, J. Wang, M. Lei, G. Xie, G. Zeng, and S. Luo, "Biosorption of zinc(II) from aqueous solution by dried activated sludge," J. Environ. Sci., vol. 22, no. 5, pp. 675-680, 2010.

[18] T. Phuengprasop, J. Sittiwong, and F. Unob, "Removal of heavy metal ions by iron oxide coated sewage sludge," J. Hazard. Mater., vol. 186, no. 1, pp. 502-507, 2011.

[19] H. L. Chiang, K. H. Lin, and H. H. Chiu, "Exhaust characteristics during the pyrolysis of $\mathrm{ZnCl} 2$ immersed biosludge," J. Hazard. Mater. vol. 229-230, pp. 233-244, 2012.

[20] F. Cheng, H. Luo, L. Hu, B. Yu, Z. Luo, and M. Fidalgo De Cortalezzi, "Sludge carbonization and activation: From hazardous waste to functional materials for water treatment," J. Environ. Chem. Eng., vol. 4, no. 4, pp. 4574-4586, 2016.

[21] A. Bhatnagar and A. K. Minocha, "Utilization of industrial waste for cadmium removal from water and immobilization in cement," Chem. Eng. J., vol. 150, pp. 145-151, 2009.
The authors would like to express their highest gratitude to Industrial Education \& Training Center 
[22] M. A. A. Zaini, M. Zakaria, S. H. Mohd.-Setapar, and M. A. CheYunus, "Sludge-adsorbents from palm oil mill effluent for methylene blue removal," J. Environ. Chem. Eng., vol. 1, no. 4, pp. 1091-1098, 2013

[23] M. Abbas, A. Zaini, and N. Yuhana, "Evaluation of Treated and Untreated Sludge from Yarn Processing Factory as Adsorbent Candidates for Dye Removal," vol. 44, no. 2, pp. 508-517, 2017.

[24] A. Iddou and M. S. Ouali, "Waste-activated sludge (WAS) as $\mathrm{Cr}$ (III) sorbent biosolid from wastewater effluent," Colloids Surfaces B Biointerfaces, vol. 66, pp. 240-245, 2008.

[25] E. Siswoyo, Y. Mihara, and S. Tanaka, "Determination of key components and adsorption capacity of a low cost adsorbent based on sludge of drinking water treatment plant to adsorb cadmium ion in water," Appl. Clay Sci., vol. 97-98, pp. 146-152, 2014.

[26] L. Yang, J. Wei, Z. Liu, J. Wang, and D. Wang, "Material prepared from drinking waterworks sludge as adsorbent for ammonium removal from wastewater," Appl. Surf. Sci., vol. 330, pp. 228-236, 2015.

[27] S. A. Abo-El-Enein, A. Shebl, and S. A. Abo El-Dahab, "Drinking water treatment sludge as an efficient adsorbent for heavy metals removal," Appl. Clay Sci., vol. 146, no. May, pp. 343-349, 2017.

[28] S. Salmariza, "Pemanfaatan Limbah Lumpur Proses Activated Sludge Industri Karet Remah Sebagai Adsorben," J. Ris. Ind., vol. VI, no. 2 pp. 175-182, 2012.

[29] S. Sy, I. Lestari, D. Kurniawati, H. Aziz, Z. Chaidir, and R. Zein, "Characterization of Waste Activated Sludge of Crumb Rubber Industry (CRI-WAS) as Adsorbent of Cd(II)," Der Pharma Chem., vol. 8, no. 18 , pp. 228-235, 2016.

[30] S. Salmariza, M. Mawardi, R. Harriyani, and M. Kasman, "Developing an Adsorbent from Sludge Waste of Crumb Rubber Industry Which is Activated by H3PO4 for Adsoption of Cr(VI)," J. Litbang Ind., vol. 4, no. 2, pp. 67-77, 2014.

[31] I. Velghe, R. Carleer, J. Yperman, S. Schreurs, and J. D'Haen, "Characterisation of adsorbents prepared by pyrolysis of sludge and sludge/disposal filter cake mix," Water Res., vol. 46, no. 8, pp. 2783 2794, 2012

[32] P. Devi and A. K. Saroha, "Utilization of sludge based adsorbents for the removal of various pollutants: A review," Sci. Total Environ., vol. 578, pp. 16-33, 2017 